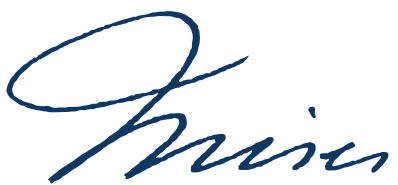

\title{
A ação empreendedora na política como causadora de custos externos na pandemia de COVID-19 e como fonte de risco de ladeiras escorregadias
}

\author{
Carlos Eduardo Carneiro Lima ${ }^{I}$ (i) 0000-0003-4645-6348 \\ Universidade Federal da Bahia, Salvador, Bahia, Brasil
}

Resumo: O objetivo do presente artigo consiste em evidenciar como os efeitos comuns e frequentemente invisíveis das medidas governamentais contra a pandemia de covid-19 estão relacionados à dinâmica dos interesses morais, materiais e políticos dos empreendedores que atuam na esfera política, contribuindo para a implementação de políticas públicas, muitas das quais geram consequências desastrosas no presente ou potencialmente no futuro. Busca-se mostrar como os empreendedores políticos com interesses diversos contribuem para os custos vistos e não vistos durante a pandemia, além de também fornecer uma perspectiva de legados negativos ao futuro, de acordo com o risco de "ladeiras escorregadias". Assim, pôde-se concluir que os problemas naturais ou normais tendem a ser reforçados pela atuação dos que buscam capturar ou mobilizar o estado, influenciando direta ou indiretamente as medidas governamentais.

Palavras-chaves: Covid-19, empreendedorismo, economia, política, custos externos.

\footnotetext{
${ }^{\mathrm{I}}$ Graduado em Economia pela Universidade Salvador (Unifacs) e mestrando em Economia pela Universidade Federal da Bahia (Ufba). E-mail: carloseduardo_cl@hotmail.com
} 


\title{
Entrepreneurial action in politics as causing external costs in the COVID-19 pandemic and as a source of risk for slippery slopes
}

\begin{abstract}
The purpose of this article is to highlight how the common and often-invisible effects of government measures against the covid-19 pandemic are related to the dynamics of the moral, material, and political interests of entrepreneurs working in the political sphere, contributing to the implementation of public policies, many of the each generate disastrous consequences in the present or potentially in the future. It seeks to show how political entrepreneurs with diverse interests contribute to the costs seen and unseen during the pandemic, as well as a perspective of negative legacies for the future, according to the risk of "slippery slopes." Thus, it was possible to conclude that natural or normal problems tend to be reinforced by those seeking to capture or mobilize the state, influencing governments' measures directly or indirectly.
\end{abstract}

Keywords: COVID-19, entrepreneurship, economy, politics, external costs.

\section{La acción emprendedora en la política como causadora de costos externos durante la pandemia de covid-19 y como fuente de riesgo de bola de nieve}

Resúmen: El objetivo del presente artículo consiste en evidenciar cómo los efectos comunes y muchas veces invisibles de las medidas gubernamentales contra la pandemia de covid-19 están relacionados a la dinámica de los intereses morales, materiales y políticos de los emprendedores que actúan en la esfera política, contribuyendo así para la implementación de políticas públicas, muchas de las cuales generan consecuencias desastrosas en el presente o potencialmente en el futuro. Se trata de mostrar cómo los emprendedores políticos con diversos intereses contribuyen para costos vistos y no vistos durante la pandemia, pero también una perspectiva de legados negativos a futuro, de acuerdo con el riesgo de "bolas de nieve". Así, se puede ver que los problemas naturales o normales tienden a ser reforzados por la actuación de los que buscan capturar o movilizar al estado, influenciando directa o indirectamente las medidas gubernamentales.

Palabras clave: Covid-19, emprendimiento, economía, política, costos externos. 


\section{Introdução}

Pandemias, definitivamente, são comuns ao longo da história e a mais recente não será a última. Muitas lições, porém, não são aprendidas e as típicas falhas de governo que tendem a ampliar a gravidade e o número de problemas que surgem nestas ocasiões não são sequer frequentemente reconhecidas, quanto mais combatidas.

No processo de definição de políticas públicas contra o covid-19, é fundamental destacar o papel dos indivíduos que, agindo de forma empreendedora, buscam, por vias legais ou ilegais, controlar, direta ou indiretamente, o poder de coerção do estado, de sorte que possam obter ganhos, ainda que os prejuízos a outros sejam severos.

Nesse sentido, em ocasiões em que se encontram a pressão popular em favor das ações governamentais "morais" de combate à disseminação da doença causada pelo SARS-CoV-2 (Severe Acute Respiratory Syndrome Coronavirus 2), os interesses materiais relacionados às decisões do governo e o potencial de ganho político/eleitoreiro, é de se esperar que não prevaleçam o interesse e a satisfação de todos aqueles que acabam saindo prejudicados, mas que sejam aprovadas as medidas que podem se traduzir em benefícios aos que visam ao controle estatal.

Mesmo assim, necessário é identificar e analisar os custos "invisíveis"1 gerados pela atuação dos empreendedores políticos no cenário de pandemia de covid-19. Com efeito, os custos podem passar a ser mais "visíveis" e há maiores chances teóricas de se incentivar reações contra outras futuras violações de direitos humanos.

Ademais, se muitas análises sobre a viabilidade das intervenções podem ser consideradas "políticas", convenientes para si ou parciais, imperativo e oportuno é revelar custos, ao invés de escondê-los², como tende a ser comum nestas análises.

Feitas essas considerações, neste artigo são destacadas algumas entre as principais intervenções realizadas pelos governos no quadro de pandemia ao redor do mundo e são expostos alguns dos seus custos. Em seguida, cabe descrever o padrão de ação dos empreendedores políticos, valendo-se do expediente à comparação com a figura do empreendedor econômico (sobretudo, à luz das teorias da Escola Austríaca de Economia). Por fim, há a análise relacionada às causas relacionadas ao processo de aprovação de políticas públicas e à perspectiva de possíveis "ladeiras escorregadias", a partir da experiência com medidas mais duras no contexto da pandemia.

\footnotetext{
1 “Entre um bom e um mau economista existe uma diferença: um se detém no efeito que se vê; o outro leva em conta tanto o efeito que se vê quanto aqueles que se devem prever." Esta citação pode ser encontrada no famoso ensaio do economista francês Frédéric Bastiat, $O$ que se vê e o que não se vê.

2 "A economia é a triste ciência de revelar custos, enquanto a política é a alegre arte de escondê-los" (autor desconhecido).
} 


\section{As Ações Governamentais em Resposta à Pandemia do Novo Coronavírus e os seus Custos "Invisíveis"}

Como é de praxe em ocasiões de pandemia, enquanto ainda não há vacina ou tratamento comprovadamente eficaz, diversas medidas de caráter não-farmacológico ou profiláticas tendem a ser implementadas, de modo que possa haver redução do contato entre as pessoas e uma eventual atenuação do risco de transmissão em larga escala.

Nesse sentido, tendem a ser empregadas diversas medidas de restrição ou proibição à circulação de pessoas em espaços públicos e privados, mas também à realização de atividades econômicas, em especial, as vistas como "não-essenciais". Via de regra, quarentenas, lockdowns, shutdowns e medidas de isolamento e distanciamento social diversas instituídas buscam, ao restringir a liberdade alheia, frear o avanço da doença.

Ações relacionadas a maiores gastos com saúde também são amplamente adotadas pelos governos, de sorte que boa parte da população possa ser privada do contato com o vírus e que o sistema de saúde público e privado não entre em colapso.

Já como resultado dos danos materiais causados pelas amplas restrições e pelos maiores gastos gerais com saúde e prevenção, diversas intervenções de caráter (macro)econômico e controles diretos ocorrem.

Embora seja razoável reconhecer que há alguns possíveis retornos brutos positivos associados a cada medida (ainda que a eficácia também possa ser e seja frequentemente contestada), cabe destacar os seus principais custos, especialmente por serem "invisíveis" - por pouco ou nunca se fazerem presentes nas discussões. O objetivo é também facilitar a análise acerca da possibilidade de que os "efeitos colaterais" dos "remédios" contra a "doença" possam ser considerados piores ou não do que a própria "doença".

As medidas de restrição à liberdade de circulação associadas às suspensões das atividades "não-essenciais" (como se as "atividades essenciais" não dependessem destas) certamente possuem um potencial destrutivo para economia e para os níveis de emprego e de renda, ao reduzirem fortemente a produção (gerando prejuízos e inúmeras falências) e o consumo. Da mesma forma, o temor de muitos restringe voluntariamente as compras e a produção. $O$ momento da pandemia é, deste modo, marcado pelo fato de que as pessoas não querem ou não podem consumir e/ou produzir. Conforme Geller (2020), visualiza-se um caso raro de choque de oferta e de demanda que traz, por um lado e por outro, maus efeitos.

Ainda que uma economia em queda possa indicar problemas evidentes, muitas das suas consequências secundárias, terciárias e além são pouco ou nada consideradas nos debates. A pobreza, a fome e a subnutrição (em especial em países pobres) são realidades preocupantes e que também matam e muito (THOMAS, 2020). No mínimo, limitam o desenvolvimento e o bem-estar e pressionam por gastos com o tratamento de muitos problemas decorrentes possíveis (FITZGERALD; NUNN; ISAACS, 2020).

A queda na atividade econômica, mesmo que alguma coisa compensada pelos benefícios temporários de renda - que não alcançam a todos ou não são, muitas vezes, suficientes, porém - também faz com que muitos cancelem planos de saúde, de acordo com o Instituto de Estudos 
de Saúde Suplementar (IESS, 2020). Logo, passam a ter de enfrentar a ineficiência que mata e lesa dos sistemas públicos de saúde.

$\mathrm{Na}$ área de educação, além dos prejuízos causados pelas falências de instituições, pela suspensão de aulas e por perdas de rendimentos, há também possíveis problemas com as mudanças na estrutura de ensino, com efeitos possíveis a serem vistos apenas a longo prazo, entretanto, conforme Fitzgerald, Nunn e Isaacs (2020).

Muitos acabam abusando de bebidas alcoólicas (e/ou outras drogas) e alimentos pouco nutritivos ou gordurosos, prejudicando a própria saúde (MCMAKEN, 2020). Contudo, pressionam as finanças de terceiros, os pagadores de impostos, aqueles sustentam o sistema público de saúde e todos os gastos governamentais relacionados a tentativas de se amenizar as consequências negativas.

Justamente num momento em que a caridade privada poderia ser reforçada, medidas restritivas acabam por reduzir muitas ações benéficas a terceiros, como nos casos de redução no número de doações de sangue e plaquetas (BRASIL, 2020).

Com base em dados do Instituto Brasileiro de Geografia e Estatística (IBGE, 2020), falências são frequentes, embora já fossem esperadas em cenários de liberdades restringidas. Entretanto, o potencial destrutivo das medidas de restrição não recai da mesma forma sobre todas as empresas, uma vez que a assimetria de tamanho e de condições financeiras, via de regra, tende a prejudicar menos as maiores empresas ou as grandes redes. Assim, há tendência para a concentração de mercado, o que pode gerar níveis mais reduzidos de produção, aumentos de preços, queda nos salários reais, menor empregabilidade, deterioração da qualidade dos produtos, etc.

Para Fitzgerald, Nunn e Isaacs (2020), o confinamento também expõe muitos ao risco de problemas familiares, a exemplo do número de casos de violência doméstica. Em adição, também tende a produzir distúrbios psicológicos, como ansiedade e depressão. As taxas de suicídio tendem a aumentar, revelando um quadro funesto para a saúde mental das pessoas (MCMAKEN, 2020). Segundo Thomas (2020), a ansiedade e o estresse gerados também contribuem para a queda da imunidade, favorecendo, inclusive, a doença causada pelo SARSCoV-2.

Já as longas temporadas dentro de casa contribuem para a ocorrência de arboviroses urbanas - dengue, zika e chikungunya e febre amarela (MARCOLINI, 2020).

É possível conceber o aumento do número de moradores de rua e pessoas vivendo em condições mais insalubres em geral, as quais tendem a ficar mais expostas a problemas diversos (SILVA; NATALINO; PINHEIRO, 2020).

Para além da controversa ideia de soltura de presidiários, a crise pode gerar problemas com aumentos na criminalidade, ainda que no futuro (KAHN, 2012). Propriedades privadas (incluindo os corpos dos indivíduos) podem sofrer danos.

Embora tenha havido um aumento de gastos gerais com saúde, isto se deveu quase que inteiramente à pandemia de covid-19. Entretanto, o aumento do gasto contra a pandemia também se deu às custas do atendimento de muitas outras áreas da saúde. Se os recursos 
são escassos, outras demandas continuam precisando de atenção e o poder público não se mostra interessado em atendê-las, os maiores gastos, destinados à construção de hospitais, à contratação de profissionais de saúde, às compras de EPIs (equipamentos de proteção individual), respiradores, álcool em gel, etc., fazem com que haja prejuízo a alguém ou a alguma área, evidentemente.

Consequentemente, cirurgias são canceladas ou adiadas, consultas não ocorrem, muitos (para além do normal) não conseguem obter tratamento, mortes súbitas aumentam e há possibilidade de que doenças graves e tratáveis não sejam diagnosticadas e tratadas a tempo (SZWARCWALD et al., 2020).

A corrupção e as fraudes tendem a aumentar: são recorrentes denúncias de desvios causados pela flexibilização de regras (como a dispensa de licitação), para além das concessões de benefícios indevidos e dos aliciamentos praticados por cidadãos interessados em aprovar projetos vantajosos para si (GONÇALVES, 2020).

No campo econômico, como resposta, sobretudo, ao risco de danos à imagem dos políticos e burocratas, diversas medidas são adotadas. Os prejuízos causados pelas restrições à liberdade e a oportunidade de ganhos políticos e econômicos impelem recursos a diversas intervenções, como os maiores gastos com assistencialismo. Vale apontar que, mesmo que se saiba que há custos indiretos envolvidos nas medidas, certas compensações são feitas apenas a partir do momento em que os problemas aparecem ou se destacam, o que indica as tradicionais deficiências de planejamento.

Frequentemente, vêm à tona também as discussões sobre controles de preços -incluindo salários, juros, câmbio, alugueis, etc. Não apenas propostas, porém, há também casos reais de implantação das medidas. De qualquer forma, a despeito da pretensão de se promover o "bemestar social" ao se tentar a imposição de limites para o preço de alguns bens (principalmente os mais essenciais), boas intenções não bastam. Como vastos exemplos históricos ensinam, as intervenções no sistema de preços geram prejuízos à produção e/ou à demanda pelos fatores de produção. Nos exemplos de fixação dos preços dos gêneros essenciais em níveis abaixo do que seriam em caso de ausência da medida, a demanda aumenta justamente num momento em que a oferta tende a ser desestimulada, gerando crises de desabastecimento. Se houver fixação de preços mínimos em níveis acima dos de mercado, como aumentos forçados dos rendimentos pagos aos fatores de produção, há uma tendência para a redução da demanda - desemprego (MISES, 2017).

Assim, os preços e os rendimentos (como salários) podem até ser fixados em níveis "humanitários", mas nada garante que haverá produtos disponíveis ou o mesmo nível de emprego dos fatores de produção. Já o descompasso gerado tende a disseminar crises e insatisfação junto ao público que teoricamente seria "beneficiado" pelas medidas.

Controles de preços também são encontrados nos sistemas monetários e financeiros regulados pelos governos. Nas frequentes ocasiões em que há reduções nas taxas de juros com objetivo de se estimular a economia (na prática, uma política de preços máximos), a demanda por empréstimos aumenta, ao mesmo tempo em que a oferta de recursos poupados 
do consumo diminui, gerando um boom de investimentos sem base em renúncias voluntárias ao consumo - ao contrário (IORIO, 2011).

Segundo de Soto (2013), sem um aumento na taxa de poupança não há, obviamente, uma queda na taxa de consumo e a consequente liberação de recursos reais úteis para o aumento da capacidade instalada. Não há tendências positivas suportáveis, fundamentadas num maior nível de renúncia ao consumo no presente em favor do consumo no futuro e na consequente liberação de fatores de produção para as etapas mais afastadas do consumidor final. Logo, o crescimento e/ou a manutenção das novas etapas mais afastadas geradas na estrutura de produção são frágeis.

Se a propensão ao consumo permanece, força-se uma posterior contração dos setores mais afastados do consumidor final, mostrando uma tendência de convergência do perfil da estrutura produtiva ao nível de preferência intertemporal real da economia. Assim, intervenções nos preços/juros e expansões creditícias tendem a viabilizar um movimento de expansão insustentável baseado em investimentos sem demanda real no futuro, em especial nos estágios mais afastados do consumidor final. Em função da correção do mercado alicerçada nas preferências dos agentes (que se mantêm pelo consumo) e no aumento da incerteza, a tendência é de crises posteriores, as quais, após a recuperação, normalmente são seguidas por novas rodadas de expansão monetária/creditícia, gerando mais booms, seguidos de busts e, assim, sucessivamente, fazendo com que a economia opere conforme uma inclinação a movimentos cíclicos de alta e baixa (DE SOTO, 2013).

Entretanto, valendo-se da ideia de que expandir moeda e facilitar o crédito sem lastro em poupança real causa um efeito benéfico na economia e que a deflação dos preços é um mal que deve ser evitado praticamente a qualquer custo, governos ao redor do mundo avançam em políticas monetárias expansionistas mais drásticas - aumentando o crédito, reduzindo juros, comprando títulos ou ativos em posse do setor financeiro, criando novas linhas de crédito especiais para grupos selecionados, etc.

Durante a pandemia, muitos governos tentam com suas políticas de quantitative easing (ou políticas similares) o de sempre: "imprimir" dinheiro. Busca-se facilitar as condições de financiamento dos gastos públicos e privados, diminuir as taxas de juros, incentivar a produção, evitar (ou postergar) crises econômicas e no mercado financeiro e impedir a deflação dos preços (destacadamente os dos ativos financeiros). Diante destes objetivos principais, compras de títulos são realizadas e o dinheiro utilizado é criado massivamente e do nada. A base monetária - especialmente pelo aumento das reservas bancárias - é expandida e os juros caem, de modo que se tente gerar benefícios à economia (RALLO, 2015).

Aumentos dos preços de produtos não-financeiros não são frequentemente significativos e isto se deve ao fato de que, em função da incerteza, o dinheiro não ingressa na "economia real", mas se concentra no sistema financeiro (inflando bolhas, sobretudo). Face ao risco de aumento de preços e de crise econômica, tanto a oferta de, como a demanda por empréstimos resistem aos movimentos expansionistas (NORTH, 2015). Em adição, pagamentos de juros pelos depósitos, incentivam a formação de reservas, em prejuízo ao crédito e à inflação dos preços. 
No entanto, a economia não passa ilesa aos (maus) efeitos da política. Comumente, prejuízos decorrem do custo relacionado ao pagamento às instituições financeiras, do maior endividamento público e da depreciação da moeda nacional (ROTHBARD, 2013). Segundo Roque (2015), taxas de câmbio (ou moedas em geral) desvalorizadas geram incertezas junto a investidores (externos, principalmente), pressionam preços para cima e promovem desindustrializações. Cabe, adicionalmente, salientar o efeito redistributivo e concentrador de renda junto aos setores ou indivíduos beneficiados.

Os subsídios incentivam não a atividade empresarial que gera valor, mas sim os ganhos por se dispor primeiro do dinheiro novo criado e por se ter vendas garantidas pelo estado, acentuando a dependência junto ao governo e privando as empresas da regulação dos consumidores e das pressões concorrenciais (MISES, 2017).

As falências, indispensáveis para que sejam liquidados os empreendimentos que consomem recursos escassos e não geram valor, também são evitadas, impedindo o duro, mas necessário, reajuste dos mercados. Assim, o capital não é direcionado dos menos capazes para os mais capazes, de modo que possam ser realocados em atividades demandadas e produtivas, mas é premiada a ineficiência (REED, 2015).

As intervenções nos juros e nos preços dos ativos distorcem os necessários sinais para atuação no mercado, favorecendo o crescimento de um ou mais setores, em prejuízo a outros (ULRICH, 2016). Se não há obrigação de eficiência, sobreinvestimentos são incentivados justamente nos setores que são beneficiados pelo governo, onde há subsídios, preços artificialmente altos sustentados pela ação estatal e demanda garantida. Já o risco moral passa a ser factível, pelos estímulos a ações irresponsáveis ou equivocadas (como maus investimentos), responsáveis por trazer prejuízos socializados, ao invés de privados (BIANCO, 2020).

Necessário dizer que as políticas expansionistas nunca são "neutras" ou isentas de custos, ainda que estes sejam relativamente baixos para quem cria o dinheiro novo - governos e o sistema bancário, que opera conforme o mecanismo de reservas fracionárias. Inclusive, mesmo que haja um benefício líquido associado a quem primeiro dispor da moeda nova, estes acabam incidindo, de fato, sobre o restante da sociedade, mesmo que apenas no futuro. Ciente disto, o benefício relacionado ao maior poder de compra de alguém gerado por expansões monetárias é sempre arcado por outro alguém na forma de redução do seu poder de compra geralmente os mais pobres, poupadores, credores, quem possui rendimento fixo, assalariados (especialmente, quem tem menor poder de negociação para pleitear reajustes salariais junto aos seus empregadores), portadores de dinheiro em espécie, entre outros (ROTHBARD, 2013).

A respeito das medidas de expansão monetária e concessão direta de benefícios de renda aos cidadãos para "alívio financeiro", mesmo que, devido ao colapso da demanda, não haja uma tendência de aumento para a maioria dos preços, pode-se discutir se há alguma serventia prática: as pessoas não precisam do dinheiro em si (como se quisessem "consumi-lo"), mas sim do que o dinheiro pode comprar. Se a produção (que é o que realmente interessa) é prejudicada, a intervenção não faz surgir mais produtos nas prateleiras, mas até o contrário, dado o risco de consumo de capital e o aumento da incerteza gerado pela inflação - gerada pelo regime (MISES, 2017). 
Se muitos poupam voluntária ou involuntariamente e se há dinheiro adicional criado na economia, os recursos tendem a ser canalizados maiormente para o mercado financeiro - sobretudo, junto a ativos reais historicamente mais seguros como reserva de valor (como ouro e prata) e rumo ao mercado de capitais. Se são frequentes imposições de juros reais e nominais negativos, é de se esperar que a renda fixa seja desestimulada e que o temor da inflação e da instabilidade econômica decorrente da política inflacionária favoreça os ativos que preservem poder de compra ou que até aumentem de valor frente às moedas nacionais. Como resultado da maior demanda por esses ativos que, por sua vez, é incentivada pela expansão monetária, o aumento tende a se dar em maior grau nos seus preços. Principalmente no mercado acionário, os preços sobem, mas descolados dos fundamentos da economia real, inflando bolhas (ULRICH, 2016).

Em caso de retomada da confiança na economia, em que haja algum sinal de recuperação, a moeda adicional criada no período da pandemia pode ser redirecionada para os gastos na "economia real", favorecendo, assim, o aumento dos preços dos produtos que forem mais demandados (MISES, 2017). Logo, a inflação de preços na sua forma mais "explícita" é apenas uma questão circunstancial: pode não ocorrer apenas enquanto durar o momento atípico.

Certamente, outros tantos efeitos da inflação poderiam ser listados, geralmente ligados à promoção em larga escala da ineficiência, ao aumento da incerteza, aos incentivos aos erros de cálculo empresarial, aos prejuízos à poupança, aos favorecimentos de uns em detrimento de outros, às distorções diversas em preços e em índices de produtividade dos setores da economia, etc. (ROTHBARD, 2013). Fatalmente, as aventuras pela heterodoxia no campo monetário causarão estragos.

Como já dito, no cenário de pandemia e intervenções do governo, além de haver incentivos à poupança voluntária por razões precaucionais e desincentivos ao consumo voluntário, também cresce o nível de poupança involuntária de quem acaba não podendo consumir - devido às restrições diversas (e quando há também uma certa manutenção da renda). Evidentemente, se a renda não é consumida, por qualquer razão que seja, há uma tendência para um maior nível de poupança. Todavia, a massa de desempregados, os prejuízos e as falências empresariais e a queda na renda tendem a fazer com que haja consumo de capital. Num cenário de duas pressões divergentes sobre o nível de riqueza, o balanço tenderá a determinar ou limitar o nível de consumo (padrão de vida) futuro - impactando positivamente em caso de aumento do nível de poupança ou negativamente em caso de redução, coeteris paribus (HAYEK, 2008). O cenário negativo, porém, é provável se as ações restritivas se prolongarem indefinidamente, diante do alto crescimento da dívida pública e da inflação e enquanto a confiança na economia não se restaurar. Neste sentido, os níveis de investimentos, de empregabilidade e de rendimentos em geral estarão limitados pelo balanço do nível de poupança (DE SOTO, 2013).

Fundamental destacar que, numa eventual situação em que os fundos emprestáveis estiverem ainda mais escassos do que normalmente já são, os juros serão naturalmente pressionados para cima, inviabilizando, em maior grau, os projetos de investimento mais dedicados ao longo prazo, mais intensivos em capital e tecnologia, mais distantes do consumidor final e que geralmente somam mais ao produto da economia. Sem capital disponível e diante 
de altos juros, pouca coisa neste sentido é possível e o encurtamento da estrutura de produção tenderá a gerar um empobrecimento geral. Se a taxa social de preferência intertemporal efetiva subir como efeito da pandemia e das medidas dos governos (como as expansões monetárias e fiscais), o efeito mais nítido é o prejuízo à poupança e aos seus impactos positivos sobre a estrutura de capital e o nível de qualidade de vida no futuro (DE SOTO, 2013).

Quando não há corte de despesas para que se possa acomodar a explosão de gastos extras com assistencialismo e saúde, mas sim queda na arrecadação devido à depressão do setor produtivo e à ampliação de isenções fiscais (embora muitas destas sejam, em si, benéficas), o efeito é o endividamento público - do setor produtivo ou das gerações futuras. Se por interesses próprios diversos, barreiras legais e/ou impasses de natureza política, o setor público não realiza sacrifícios, os custos acabam recaindo sobre o setor privado, ainda que no futuro e "com juros".

Endividar-se significa, basicamente, antecipar fluxos futuros de renda, de modo que seja possível melhorar a própria situação no presente. Contudo, estes benefícios extraordinários não são gratuitos, pois acabam custando no futuro na forma de diversas possibilidades negativas como aumentos dos impostos, dos preços, dos juros, dos preços do dólar, etc. (SHOSTAK, 2010). Em linhas gerais, há a possibilidade de se reforçar os desincentivos à produção, gerando pobreza.

Implacavelmente, todos esses custos e outros mais serão arcados por muitos ou pela maioria, dado o prejuízo sobre as finanças públicas (neste caso, outro nome para pagadores de impostos ou setor privado) ou sobre a produtividade da economia em geral. Entretanto, a visão de muitos sobre os problemas gerados pode estar turva justamente porque algumas consequências ainda não se apresentaram ou ainda não se apresentaram com intensidade "considerável", embora nada disto signifique sucesso das medidas adotadas em resposta à pandemia do novo coronavírus.

\section{O Empreendedorismo Econômico e o Empreendedorismo Político}

A Escola Austríaca, a despeito da ignorância - involuntária ou voluntária - de muitos, merece um papel de destaque no histórico da evolução do pensamento econômico por tratar de temas essenciais em qualquer análise relevante dos processos de mercado: a função empresarial e o papel fundamental do empreendedor na economia.

Mesmo que a visão normalmente se restrinja mais aos empreendedores mais tradicionais e situados no setor privado (empresários, sobretudo) que, se bem-sucedidos em suas empreitadas, criam valor, boa parte do núcleo da teoria também se aplica aos empreendedores que atuam no campo político para capturar o estado.

Segundo Gianturco (2020), entre os empreendedores políticos, encontram-se não apenas os políticos, mas os lobistas, os burocratas e os cidadãos comuns (entre os mais engajados). Vale apontar as associações e organizações formadas por cidadãos comuns com fins de controle direto ou indireto das ações públicas, fenômeno, inclusive, crescente no Brasil nos últimos anos. Em suma, podem ser incluídos todos aqueles que, agindo de forma empreendedora, de 
alguma forma específica, buscam influenciar as decisões do governo (de dentro ou de fora deste) e se valer do seu monopólio da violência para espoliar os outros e atender interesses próprios.

Mesmo que o objetivo-mor seja atender interesses próprios (em especial obter lucro econômico e renda política), não é possível afirmar, a priori, que todos agem de modo "nãoaltruísta" ou que sejam todos mal-intencionados. De fato, a característica comum é a busca por benefícios particulares, ainda que estes possam ser atendidos também mediante a atenção a uma causa "social" que muitos venham a defender - situação em que a utilidade alheia também promove a utilidade pessoal. Para que alcancem estes estágios, porém, os representantes da classe, as "suas ideias" ou os "seus ideais" precisam alcançar o poder e neste permanecer (GIANTURCO, 2020).

Segundo a tradição de estudo da Escola Austríaca de Economia, a função empresarial - uma categoria da ação humana - é exercida ao se partir da percepção de possibilidades de lucro. Ante estes fins cujo valor é subjetivo, os empreendedores são motivados a buscar os meios mais úteis, de modo que se torne mais fácil ou simples o alcance dos seus objetivos. A ação empreendedora também se vale da ponderação subjetiva de benefícios em relação aos custos de cada alternativa (IORIO, 2011).

Diante das opções, cabe aos agentes mais racionais ordená-las com base na utilidade marginal de cada: nas primeiras posições, apenas as opções mais valorizadas, uma vez que não há como se fazer tudo e se atender a todas as demandas se os recursos são escassos. Assim, a hierarquia de utilidade (valor) tende a ser considerada ao longo dos processos (IORIO, 2011). Vale evidenciar que há sempre renúncia a outros usos úteis para os recursos necessários em cada plano de ação, ideia ligada ao conceito de custo de oportunidade, como teorizado por Wieser (1927).

A lei da preferência intertemporal, como não poderia deixar de ser, também se faz presente, considerando-se que, em cenários iguais em circunstâncias, os indivíduos preferem atingir seus objetivos da forma mais rápida possível. Em outras palavras, se os empreendedores de qualquer natureza procuram desfechos com êxito no momento mais próximo possível (no limite, instantaneamente), a opção mais distante no tempo, se igual em termos de condições (sobretudo, quanto ao retorno) à opção mais próxima, jamais será escolhida. Consequentemente, os processos mais demorados só terão espaço caso venham acompanhados de um retorno maior ou um prêmio que possa compensar os custos com a renúncia e com a espera (IORIO, 2011).

Ao se ter em mente que há diferenças entre as formas como os indivíduos encaram as suas necessidades de consumo ao longo do tempo (entendido em sua concepção dinâmica e real), o grau de preferência intertemporal também acabará por definir quais planos serão escolhidos e quais métodos serão empregados. Para um mesmo indivíduo e em igualdade de condições externas, um padrão de comportamento mais ou menos imediatista tende a fazer com que os planos, os meios e, consequentemente, os resultados variem (HOPPE, 2014).

Os empreendedores de ambas as esferas também comprometem recursos hoje conforme a expectativa de colherem lucros amanhã. Neste sentido, há o papel essencial para a necessidade de algum grau de acerto em suas estimativas, uma vez que os resultados, se colhidos apenas 
no futuro, são incertos e que os agentes não dispõem de todo o conhecimento necessário para executar as ações e acertar impecavelmente. Evidentemente, erros de cálculo são comuns, produzem efeitos nocivos e expulsam muitos do ambiente em que atuam (MISES, 2017).

Dadas as condições indissociáveis ao ser humano de limitação de conhecimento e de incerteza quanto ao futuro, a função empresarial é inerentemente especulativa: os meios empregados no presente possuem custos certos, enquanto as receitas e os lucros do futuro são incertos (BARBIERI, 2001). Assim, os empreendedores incorrem em riscos ao tentarem estimar as receitas e os ganhos no futuro. Diante disto, resta-lhes definir as metas e uma forma mais apropriada de como irão alocar os recursos, sabendo que o futuro é sempre incerto e que pouco sabem.

Nos processos políticos e de mercado, os agentes não podem se desligar tanto dos problemas relacionados à informação, como da possibilidade de ocorrência de eventos não-previstos que levem os resultados a outros patamares. Logo, a incerteza genuína (não-probabilística) é a regra. Os indivíduos, embora racionais por buscarem uma mudança para melhor da própria situação, não são capazes de deter toda a informação necessária e nem de prever precisamente a ação humana e o curso futuro da história (IORIO, 2011). Tendo-se isto em mente, os acertos tendem a decorrer dos processos de tentativa e erro (da experiência prática), os quais podem ser mais bem definidos na forma tentativa, erro, aprendizado e ajuste, uma sequência de passos que tende a incorporar a lição (conhecimento) obtida após as falhas e/ou as omissões nas novas empreitadas em busca de sucesso.

Com base na visão de Kirzner (2012), cabe ao empreendedor se pôr em estado de alerta constante quanto ao surgimento de oportunidades de lucro que ainda não foram descobertas ou que têm sido negligenciadas por outros competidores. Uma associação pode ser feita com o empreendedor político que busca constantemente o descobrimento de brechas institucionais/ legais que permitam a sua atuação.

Assim como os empreendedores tradicionais do setor privado possuem como referência as demandas dos consumidores do mercado, os empreendedores políticos também se apoiam em demandas que julgam não atendidas parcial ou inteiramente para que atuem no meio político e obtenham sucesso (MILL, 1996). Estas ações são comuns em diversos exemplos práticos e históricos de partidos políticos e organizações não-governamentais que exploram as necessidades alheias e que determinam as suas ações a partir da identificação de carências ou lacunas de representatividade no meio político (sobretudo, quando se envolve causas "em alta").

Como explica Iorio (2011), após a escolha de um determinado curso de ação, as suas consequências também dependerão, mais ou menos, dos demais cursos de ação que os outros agentes escolheram, estão escolhendo ou ainda irão escolher. Assim, empreender implica jogar e usar estratégias, o que exige mobilização de recursos, tanto para que certos níveis sejam alcançados, como para que certas posições sejam mantidas. Neste sentido, envolve-se meios legais e/ou ilegais, ainda que nada disto necessariamente guarde uma relação sinônima com ações morais. 
Dentro da estrutura que compreende ambas as modalidades, pode-se reconhecer que, assim como em mercados, o ambiente político ou em torno do poder do estado (por sua profusão de recursos teoricamente disponíveis para captura) também é marcado muitas vezes por concorrência. No jogo disputado pelos empreendedores políticos, a assimetria de tamanho e poder entre os players também é a regra. Isto acaba por influenciar o curso das ações e o padrão de comportamento/estratégia.

Não há também como se descartar a ideia de ação empreendedora no plano da política pautada na criatividade, na inventividade e na inovação. Com efeito, mesmo nestes meios, os métodos de expropriação podem ser cada vez mais sofisticados, valendo-se muitas vezes de avanços tecnológicos e da exploração do conhecimento e da sagacidade do ser humano. Igualmente, as comuns ações coletivas buscam, pela união de forças e pela divisão do trabalho, melhores resultados.

Para além do que já foi dito, porém, principalmente as consequências das ações de ambos os tipos de empreendedor tendem a ser totalmente diferentes.

Evidentemente, os empreendedores políticos não agem conforme a lógica de mercado. As trocas voluntárias dão lugar à luta pela reivindicação da renda alheia. O esforço se concentra mais na criação ou manutenção de dispositivos legais benéficos para si e maléficos para outros do que nas atividades produtivas tradicionais, que servem aos outros (e não apenas a si próprio) e agregam valor. A lógica no âmbito político é distinta da presente nos empreendimentos tradicionais, uma vez que não se atua conforme um padrão de transações voluntárias ou de ações livres e espontâneas, mas sim mediante os expedientes que promovem prejuízos a outros - os perdedores, entre os rivais do ringue de disputa política e terceiros, como o restante da sociedade. Em jogo, sempre a capacidade de mobilizar (desviar) lícita ou ilicitamente o dinheiro "público" ou as decisões do governo para que interesses próprios sejam atendidos.

Ao contrário dos empreendedores que visam à captura estatal, os empreendedores econômicos mais perspicazes (aqueles que acertam mais no cálculo econômico/empresarial) atendem demandas genuínas de mercado, melhorando, assim, a situação das partes envolvidas nas trocas (MISES, 2017). Logo, é possível depreender que, enquanto agentes que seguem a lógica de paz e cooperação presente nas transações voluntárias somam, aqueles que procuram capturar o estado subtraem. Basicamente, o elemento central que constitui a diferença se resume na capacidade de gerar maior coordenação ou não para o mercado, o que impele a compreensão de como estes efeitos se desdobram em novos efeitos sobre o bem-estar dos indivíduos envolvidos ou não envolvidos no processo gerador dos impactos.

Se há, por parte dos empreendedores, uma imprescindível função social ligada à relativa atenção às demandas de mercado, há um maior encontro de interesses em que ambos os lados - oferta e demanda - ganham. Os planos e intenções de ambos são relativamente menos frustrados. Há cooperação, bem-estar e ganhos mútuos.

Como é possível concluir ao se tomar a teoria misesiana da ação, as trocas só são possíveis a partir do momento em que ambas as partes veem vantagens nestas, ou seja, um valor mais elevado para que o outro oferece do que o que se oferece em contrapartida. Do contrário, a 
transação não ocorreria, dado que a ideia de sempre se buscar um fim positivo em tudo que se faz é o mote da ação humana (MISES, 2017).

A capacidade e a intenção de mobilizar os recursos também limitam a capacidade de coordenação. Diante disto, as oportunidades de se obter retorno, ao abrirem espaço para o empreendedorismo econômico, dão vazão à possibilidade de que os recursos (como o conhecimento) sejam utilizados, de modo que se desdobrem em coordenação e bem-estar. Vale destacar que, ainda que um processo similar também possa ocorrer no âmbito da política, o efeito é diametralmente oposto.

O empreendedorismo econômico "puro" promove, portanto, uma maior harmonia de interesses e um maior grau de satisfação. Além disto, a satisfação é mútua entre os agentes envolvidos, ao contrário do que acontece nos modelos de soma não-positiva.

Já pelas vias políticas, para além do fato de que o sucesso de um se dá, necessária e obrigatoriamente, às custas dos outros, as ações geram reações, distorções e consequências não-intencionais negativas. Conforme as ideias trazidas por Iorio (2011), pode-se entender que o recurso à coerção, mesmo que por razões "altruístas", promove maiores dificuldades em se atingir estes objetivos ligados à "moral". Falha-se na medida em que a descoordenação aumenta e que desajustes são gerados.

Certamente, é de se esperar que o expediente à imposição contrarie interesses privados - os objetivos originais, aqueles que seriam perseguidos em caso de ausência de coação governamental. Entretanto, muitos não aceitam passivamente as ordens ou se portam da mesma forma, como se nada tivesse ocorrido. Ao contrário, como resultado, torna-se comum que haja desincentivos e reações, a exemplo de desestímulos à atividade econômica ou de novos rounds na luta no ringue da política. Porém, isto afeta ainda mais a capacidade de haver alguma coordenação e os maus resultados econômicos passam a ser a regra. Conforme esta lógica, pode-se entender como as políticas públicas costumam falhar em atingir os seus objetivos teoricamente nobres: o problema também está na própria coerção.

A respeito das visões sobre os processos de mercado e os "processos políticos", Ludwig Lachmann também tem o que contribuir, mesmo que indiretamente. Ainda que o autor rejeite a ideia mais comum na Escola Austríaca de que há uma certa tendência endógena ao mercado rumo ao estado de equilíbrio (que não é atingido, porém, devido aos "acidentes de percurso" mudanças inesperadas), a noção de forças desequilibradoras e forças equilibradoras coexistentes é essencial para que se compreenda a ideia de efeito agregado líquido no sistema (BARBIERI, 2001). Com efeito, a incidência simultânea de ambas as forças empreendedoras ocorre, mais ou menos, na totalidade dos países ao redor do mundo. Logo, convivem (em desarmonia) tanto os empreendedores econômicos tradicionais, como os políticos.

Em regimes mistos, onde coexistem ambos, o curso da geração líquida de riqueza e valor é determinado pelo balanço entre ambas as forças: a positiva dos empreendimentos que produzem e a negativa dos empreendedores que violam direitos alheios. De fato, enquanto uns empreendem e trabalham, servindo como numerador para a economia, outros, (des)servindo como denominador (para valores maiores do que 1 nesta metáfora, cabe dizer, de acordo com 
a matemática), também empreendem e trabalham, mas para tomar ou impedir o bem-estar alheio, de modo que extraiam benefícios privados.

Ao se ter noção de que as medidas coercitivas de redistribuição de renda destroem renda ao desincentivarem, em termos gerais, a atividade produtiva tanto da parte que tem seus recursos confiscados, como da parte que recebe estes recursos, pode-se compreender o efeito deletério para a economia resultante da ação de muitos que se dedicam às tentativas de controle do estado e a sua capacidade de obter renda coercitivamente e redistribuí-la. Estes entendimentos também permitem reconhecer se, em linhas gerais, prevalece mais o processo de criação de renda ou o processo de redistribuição destrutiva desta. De posse disto, é possível visualizar qual o futuro provável de uma sociedade - se a riqueza ou a pobreza - da mesma forma que é possível a qualquer indivíduo que reconheça o seu lugar - entre os favorecidos ou os prejudicados - saber qual a tendência para o seu desenvolvimento pessoal.

Em países em que as relações econômicas "puras" são fortemente controladas ou restringidas pela legislação, é de se esperar que prevaleçam as relações políticas (LEONI, 2010). Substitui-se a liberdade pela força, na medida em que os ganhos legítimos não são possíveis ou são fortemente limitados pelo poder estatal. Como resultado da ausência de liberdade, predomina o sistema em que há redistribuição forçada de recursos de uns em favor de outros. Como resultado da ausência de liberdade, portanto, predomina o empreendedorismo político.

Independentemente do sistema, os agentes buscam mobilizar esforços para explorar as oportunidades disponíveis que lhes permitam alcançar maiores graus de satisfação (SMITH, 2009). Mesmo limitados pelo quadro institucional (relacionado à estrutura de incentivos), numa eventual situação em que as vias pacíficas e os meios de cooperação não sejam possíveis ou sejam "pouco atrativos", há uma tendência para que a força - a lógica da política - se imponha e prevaleça. Entretanto, pelos riscos de se passar mensagens pouco populares, a tendência é a busca por estratégias sofisticadas que permitam que as ações no meio político sejam legitimadas tanto pelos aplausos dos favorecidos, como pelo apoio dos espoliados (SENNHOLZ, 2017).

Em oposição à sagacidade e ao espírito de iniciativa dos empreendedores econômicos, a capacidade de persuasão moral, o poder econômico e a condição de agente oficial de deliberação das medidas legais são, nesses cenários, as maiores armas que se pode ter na guerra pela espoliação alheia em benefício próprio.

Além da escassez de recursos, há as instituições, que podem funcionar como forças de dissuasão, inviabilizando muitos planos de ação na política. É de se esperar que em países onde as instituições não funcionam a contento e em que as leis (leis naturais) e ordens espontâneas não imperam, mas sim a influência direta e indireta de homens autointeressados na legislação, o curso das medidas seja orientado em favor de uns poucos, havendo prejuízo para o restante da sociedade (LEONI, 2010).

Oportunidades como essas favorecem inteiramente (quase que naturalmente) a busca constante pela influência nas ações do governo, seja por razões ditas altruístas e ligadas ao desejo de bem-comum, seja em contextos de interesses materiais diretos e/ou seja pelos desejos de se obter ganhos políticos/eleitoreiros. Esse padrão é "normal", mas, especialmente 
em contextos de calamidade pública - pandemias, catástrofes naturais ou guerras -, tende a ser reforçado e a obter certo destaque.

\section{A Atuação dos Empreendedores Políticos como a Causa Fundamental dos Problemas Gerados e o Consequente Risco de Ladeiras Escorregadias}

Em contextos de pandemias e políticas públicas relacionadas, muitos agem para influenciar as decisões com motivações altruístas ou não. Os ganhos, de fato, podem ser de diversas naturezas, não apenas os econômicos próprios e diretos.

Considerando-se esses fundamentos teóricos, cabe destacar o conceito de "batistas e contrabandistas" (bootleggers and baptists), concebido por Yandle (1983). Resumidamente, trata-se de uma ocasião em que grupos de interesse com motivações distintas acabam se situando no mesmo lado - a favor ou contra - quanto à aprovação de uma certa intervenção governamental. Assim, mesmo que por razões radicalmente diferentes, ambos acabam "concordando" (GIANTURCO, 2020).

A teoria sobre batistas e contrabandistas presentes em discussões sobre as ações do governo são úteis para a análise que pretenda identificar e classificar de forma mais precisa quais são os grupos interessados e visualizar por quais razões os grupos de interesse defendem suas posições. Igualmente, pode-se compreender mais facilmente como se dá o processo político de implementação de políticas públicas.

Nas ocasiões em que se discutiu restrições ao consumo de álcool nos EUA ao longo da história (como no caso da Lei Seca, vigente entre 1920 e 1933), destaque para os "batistas", cidadãos interessados na proibição de álcool por razões morais, e para os "contrabandistas", cidadãos interessados na exploração do mercado negro de bebidas alcoólicas (GIANTURCO, 2020). Ambos podem ser vistos como "aliados históricos" em favor da proibição, ainda que a moral dos primeiros possa se opor à atuação dos segundos. Esta condição de "união", portanto, se dava mais em termos práticos.

Especialmente devido à influência da imprensa (ligada ao governo ou não), muitos indivíduos acabaram apoiando as medidas de tentativa de controle do avanço do covid-19. Mesmo que em detrimento da própria liberdade, da economia do país e, inclusive, da condição financeira própria (em muitos casos), a atuação política - também motivada por sinceros ideais morais (vale frisar) - buscou pressionar o governo por respostas à pandemia - com braço forte e mão visível.

No âmbito da política, sempre há aqueles, ditos mais abnegados, que se valem da "moral" para defender a instituição de alguma regulação ou legislação específica (GIANTURCO, 2020). Contudo, ainda que as suas motivações possam estar realmente ligadas a um ideal de caridade para com o próximo 3 , muitas vezes ignora-se completamente (até mesmo por "inocência") os custos externos decorrentes das providências tomadas pelos governos, além dos equívocos e

\footnotetext{
${ }^{3}$ Entretanto, ainda que se diga que a motivação é a caridade, isto não significa que seja, de fato, dado o expediente à coerção, o uso de recursos alheios e os inúmeros danos causados a terceiros.
} 
das imperfeições características destes. De posse destas ideias, torna-se fácil a associação de boa parte dos cidadãos que, em meio à pandemia, pressionaram o governo por ações (tendo por base o altruísmo) aos "batistas" originais da história. É o apoio de muitos "paladinos da moral e da virtude" que facilita e desobstrui o trânsito das medidas e causa, mesmo que indiretamente, muitos dos seus efeitos nefastos.

Do outro lado, os contrabandistas, com fins "menos nobres". Os contrabandistas são todos aqueles que atuam para que as regulações sejam implantadas, de sorte que possam explorar a possibilidade de atuação nas brechas da lei e atingir seus próprios objetivos (GIANTURCO, 2020). Dado o risco de reações negativas na opinião pública, os contrabandistas se veem frequentemente obrigados a se colocar ao lado das causas "mais nobres" e até a se aliar aos batistas, aproveitando os esforços destes. Paralelamente, também tendem a agir por "debaixo dos panos", em favor do advento das regulações - desfechos positivos e oportunidades para ganhos materiais.

As regulações, ao criarem custos e limites para atuação das empresas, acabam erguendo barreiras à entrada e/ou impondo dificuldades para que muitos continuem no mercado, gerando comuns prejuízos à produção e à eficiência econômica. Diante destas imposições "de cima para baixo", que criam obstáculos à atuação de muitos atores (incluindo competidores potenciais), há estímulos à concentração do mercado, favorecendo o surgimento de cartéis e monopólios (ROQUE, 2009).

Em acréscimo, há também a possibilidade de que intervenções nos mercados formais/ legais impulsionem a formação de cartéis e monopólios nos mercados negros que são resultantes destas intervenções (em cenários de demanda pouco elástica). Há, nestes contextos, um fenômeno de cartelização indireta ou cruzada. Em caso de proibições ou pesadas restrições a certos produtos demandados, por exemplo, a consequente imposição de maiores riscos e custos também para a atuação ilegal faz com que muitos não se disponham a encarar estas barreiras. Consequentemente, a tendência é uma situação em que apenas os mais "corajosos" ou os mais capazes de lidar com uma situação mais adversa atuem sem muita concorrência, podendo cobrar maiores preços, entregar qualidades inferiores e até praticar abusos diversos. Assim, podem ser justificados os interesses de muitos contrabandistas e as suas demandas por regulações: estas podem significar oportunidades de ganhos expressivos que podem muito bem não ser possíveis ou mais fáceis nos empreendimentos legais.

No contexto político e econômico da pandemia, os contrabandistas podem ser vistos por todos os lados, em todas as áreas em que o governo se dispôs a atuar e acabou atuando. Se o governo, ao tomar recursos aos montes e com regularidade, pode gerar um nível estável e até crescente de receita para indivíduos associados (aqueles que vendem para governo, por exemplo), há interesse destes em muitas das suas medidas. Certamente, a ideia de receber uma renda mais certa e em maiores volumes atrai muitos "adeptos" das medidas e "defensores" dos seus "propósitos nobres".

Embora haja também destaque para os casos de corrupção e fraudes envolvendo contrabandistas, não existem apenas exemplos relacionados às vantagens que os indivíduos ligados diretamente ao governo obtêm, posto que muitos que atuam em setores da esfera 
privada em alta em meio à pandemia também têm muito o que ganhar ao apoiarem as tentativas de contenção do vírus. Muitos nestas condições tendem a apoiar prolongamentos ou intensificações das medidas, aliás.

Feitas essas considerações, para além da análise da dinâmica de atuação de batistas e contrabandistas, é essencial a compreensão do papel daqueles que detêm o poder de decisão final: os políticos - com seus interesses, sobretudo os eleitoreiros. Ainda que estes atores também possam se portar conforme ideais morais ou interesses materiais diretos, vale também destacar este outro aspecto. Assim, de acordo com a Figura 1, no processo de definição e aprovação das políticas públicas, soma-se ao impulso moral dos batistas e à motivação econômica direta dos contrabandistas, os interesses políticos, ligados ao alcance do poder e à permanência neste.

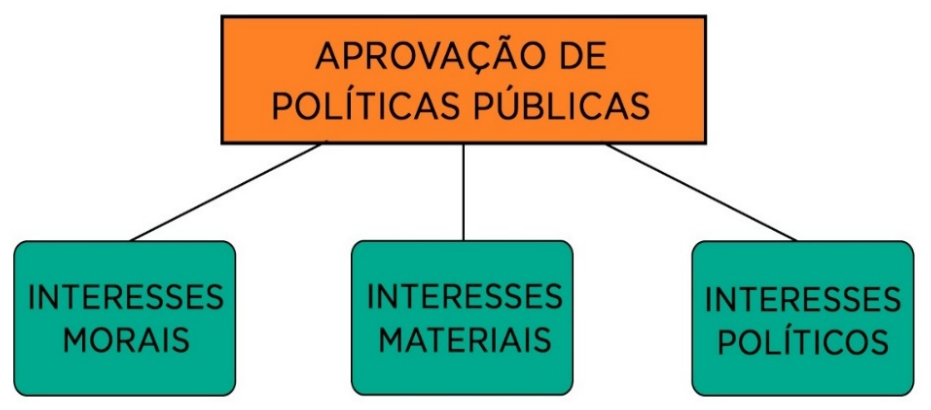

Figura 1. Ilustração do esquema de aprovação de políticas públicas.

Fonte: Elaboração própria.

Conforme a lógica de Adam Smith (2009), o homem busca os próprios interesses em primeiro lugar. No governo, evidentemente, não há como se fugir a essa regra. Diante disto, o sucesso de batistas e contrabandistas depende basicamente da possibilidade de que as medidas que apoiem também agradem os políticos. Se reconhecem que os interesses destes não podem ser contrariados, tendem a facilitar o alcance dos próprios objetivos, inclusive. Logo, os interesses precisam se alinhar de alguma forma.

A análise histórica da Lei Seca nos EUA permite identificar que houve uma poderosa e necessária coalizão (mais em termos práticos, devido ao fim em comum) para o seu advento, a qual também envolveu congressistas com distintas ideologias ${ }^{4}$ (OKRENT, 2010). Quando há interesses em jogo, um fim comum e acordos tácitos, mesmo que o benefício almejado varie, pode-se entender como as medidas são aprovadas.

Saber quais os interesses e motivações dos "congressistas" (figura para os políticos em geral e de qualquer poder), para além dos interesses e motivações dos "batistas" e dos "contrabandistas", é essencial para que haja uma melhor compreensão dos processos de instituição de políticas públicas. Por mais que uma ação pública seja moral ou que traga eficiência

\footnotetext{
${ }^{4}$ Segundo o autor, a coalizão tácita entre os congressistas da época envolveu alas tão diferentes como a racista, a progressista, a sufragista, a populista (incluindo um auxiliar socialista) e a nativista. Os votos pela proibição, porém, foram mais uma tentativa de impulso a ideologias e causas próprias que, inclusive, pouco tinham a ver com o álcool. Evidencia-se, assim, o peso do interesse político e o comum comportamento oportunista.
} 
para a economia ("desintervenções", por exemplo), a demanda só tenderá a ser atendida em caso de trazer, de quebra, também um potencial de soma ao capital político destes atores. Da mesma forma, mesmo que um projeto conte com o reforço das influências que envolvam lobby ou "dinheiro", se não for conveniente ou o bastante para os políticos, dificilmente irá passar.

Se sempre cabe aos políticos, por suas próprias posições de autoridade garantidas pelo monopólio da força, a palavra final ou o poder de deliberar ou não, os seus interesses são, inclusive, os mais relevantes para análise. Sem o devido atendimento aos seus interesses, os planos baseados na ética/moral ou em interesses econômicos podem ser frustrados. Portanto, o interesse principal a ser atendido para que algo seja feito é a capacidade que as medidas possuem em se reverter em popularidade e capital político. Ao se levar em consideração que eleger-se, ficar no poder com alta popularidade e, finalmente, reeleger-se são os fins primeiros dos políticos, tudo mais é acessório e secundário e só será levado a cabo, caso permitam que estes objetivos sejam alcançados mais facilmente.

Em momentos de calamidade pública, quando a maioria da população apoia algo em nome do altruísmo (como no contexto da pandemia), além de haver um comum arrefecimento da fiscalização das ações do governo, há a ocasião perfeita para que os políticos possam agregar ao seu "estoque" de capital político, o que se mostrará útil nas próximas eleições. Importante destacar que a pandemia de covid-19 é apenas o pretexto excepcional atual e recente, uma vez que outros podem surgir, como em ocasiões de guerra ou de catástrofes naturais, para além das ocasiões "normais", em que a política se vale da força para espoliar.

Se o apelo moral ostensivo e a possibilidade de lucro político se aliarem à oportunidade de ganhos materiais que podem ser obtidos por alguns indivíduos, há o encontro perfeito (a comunhão perfeita) de interesses ou, em outras palavras, "coordenação política" - a despeito do já tratado efeito negativo de descoordenação sobre a economia. Com efeito, a instituição da política pública em questão passa a ser praticamente certa e eventuais debates podem vir a ser meras formalidades obrigatórias.

Pagam, como não poderia deixar de ser, todos aqueles que não foram capazes de mobilizar o poder público. De qualquer forma, mesmo que os possíveis danos a estes indivíduos fossem considerados, as suas demandas podem estar associadas a um menor retorno político. Vê-se, assim, a ação empreendedora política na prática, pois, como o interesse próprio é prioritário, tudo o mais (principalmente, as demandas das massas desorganizadas que esperam algo do estado) pode estar sujeito a ideia de que só receberá atenção no caso de indicar, em contrapartida, alguma viabilidade política. Sem recompensa neste sentido, não há muitos incentivos a se incorrer em custos. Logo, as demandas dos indivíduos são, na prática, meramente uma fonte de prejuízo ou uma fonte de lucro - condição que dependerá da ocasião.

Como visto, os custos das ações não são apenas vistos no presente (ainda que sequer sejam "vistos" por muitos no presente), mas também representam risco de problemas futuros, após a pandemia. Neste sentido, é fundamental enfatizar também que a experiência com a violação de direitos humanos (para além do que já é normal) causada pela ação dos empreendedores políticos traz o risco de que a "sociedade" possa ter caído numa "ladeira escorregadia" ou que tenha botado pelo menos um pé nesta. 
Na análise, sobretudo, de muitos fenômenos sociais, o efeito ladeira (ou pista) escorregadia (slippery slope effect) se faz presente quando um indivíduo, ao dar uma brecha para algo menor (com baixo potencial ofensivo), acaba por abrir espaço - um precedente para transgressões potencialmente fatais para si ou para outros - para que medidas mais graves, drásticas e com maior potencial ofensivo sejam realizadas, de modo que o risco de problemas seja ampliado e que possa não haver mais volta. A figura se vale da ideia de que, uma vez que se ponha os pés numa ladeira ou pista escorregadia, muito provavelmente, não haverá muitas chances de haver escapatória. Logo, pequenas concessões podem levar a grandes concessões cujos infortúnios associados são possivelmente graves (RIZZO; WHITMAN, 2003).

Um mero exemplo comum do efeito - que, de certa forma, também acompanha as teorias de Mises (2017) e Hayek (2010) - se encontra nas situações em que, por razões diversas, a regulação, ao não atingir seus objetivos, acaba dando lugar a outras novas, as quais também tendem a não funcionar, favorecendo o surgimento de novas regulações, que tenderão a ser cada vez mais rígidas e abrangentes, mas que também não funcionarão e exigirão outras mais e assim por diante, até que se entre numa espiral negativa, que se forme um círculo vicioso cumulativo ou que se vire uma bola de neve. Conforme o esquema trazido na Figura 2, nestas ocasiões, é o primeiro passo, a primeira brecha para algo mais leve e menos sério que pode dar vazão a um vício com efeitos potencialmente destrutivos no futuro - para si ou para outrem.

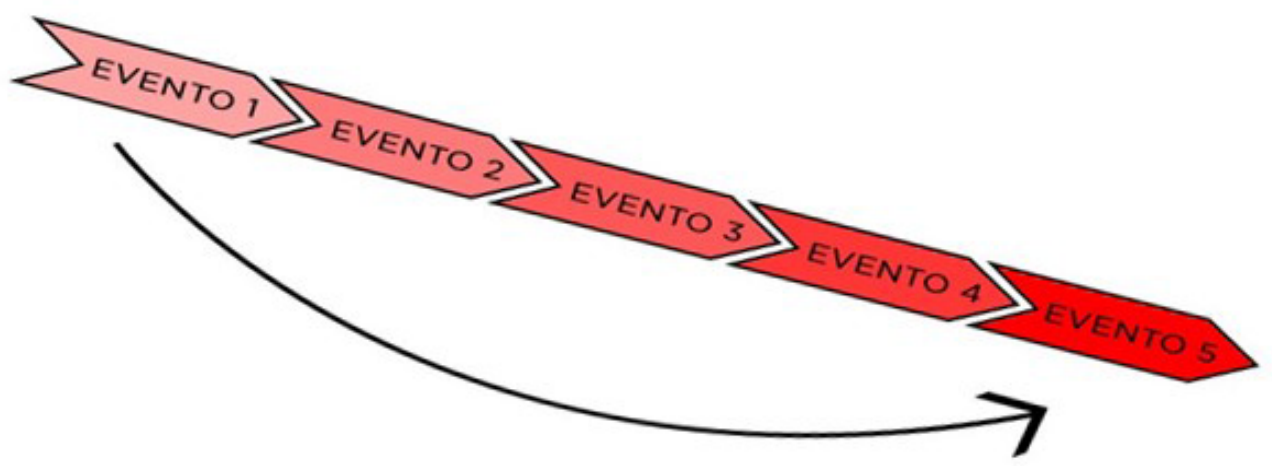

Figura 2. Esquema ilustrativo do efeito ladeira escorregadia.

Fonte: Elaboração própria.

Diante das muitas experiências que governos tiveram com o autoritarismo exacerbado durante a pandemia (medidas draconianas), não é desprezível a ideia de que as coisas possam se agravar ou de que certas medidas ou práticas negativas tenham vindo para ficar, como o "novo normal".

Se o cenário de pandemia pôde ter dado certos "empurrões" iniciais, de modo que se tenha caído na "ladeira escorregadia", não se sabe ainda, de fato. Contudo, a análise da experiência histórica é sempre útil para mostrar e alertar que legados negativos de crises aos momentos "não-atípicos" futuros são mais frequentes do que se imagina. 


\section{Conclusão}

Na análise econômica e política das regulações e legislações (do direito em geral), é imprescindível a compreensão tanto das suas causas, como das suas consequências - a ideia de saber de onde se vem e para onde se vai. Útil também é a ciência das limitações e dos interesses de quem está no centro das decisões: o governo.

Se é possível visualizar a ação dos empreendedores políticos bem-sucedidos na tentativa de capturar o estado como a causa de muitos problemas, necessárias são reações em defesa contra os ataques perpetrados. Neste sentido, a tarefa primordial consiste em fazer com que os "custos invisíveis" passem a ser mais "vistos" por meio da disseminação da informação. Ao se partir disto, a "raiz" do problema - a atuação perniciosa dos empreendedores políticos - pode começar a ser "arrancada", de tal modo que possa um dia prevalecer a lógica da liberdade, e não a da coerção.

Pode-se dizer que, mesmo que se os indivíduos espoliados tivessem sido privados do fardo dos interesses dos empreendedores políticos que se traduzem em intervenções (de sorte que o orçamento não tivesse sido alvo de desvios extras), ainda assim, haveria muita coisa a se criticar. Decerto, as falhas ligadas aos incentivos e à informação ainda fariam com que a ineficiência fosse a norma e com que os problemas fossem inúmeros, embora possivelmente menores em quantidade e em tamanho.

Se os danos causados pelo governo em cenários sem pandemia já são elevados, obviamente, estes mesmos cenários com a adição de uma pandemia "sem desvios" seriam ocasiões ainda ruins e piores. Entretanto, pior mesmo é o cenário real, em que se reúnem a tradicional e peculiar ineficiência do governo em termos de incentivos e informação, os problemas naturais em pandemias e as dificuldades extras causadas pelas ações dos empreendedores políticos interessados na expropriação alheia.

Ao se parafrasear Thomas Sowell, num mundo de escassez, não há soluções, mas apenas compensações (THOMAS, 2020). Onde os problemas se amontoam e os recursos para que se tente solucioná-los são escassos, as escolhas apenas acabam por tentar satisfazer as demandas mais urgentes e importantes, o que sempre acarreta a não-atenção total às outras demandas. Deste modo, a necessidade de alocação e realocação de recursos escassos, com usos alternativos num cenário de necessidades teoricamente ilimitadas, implica escolhas e renúncias obrigatórias.

Decerto, não há um infinito de recursos que permita resolver inteiramente todos os problemas existentes. Entretanto, se o sucesso contra a pandemia é um desafio às ações públicas e privadas, que, ao menos, outros não sejam adicionados. A questão, porém, é a possibilidade de que os empreendedores políticos sejam os responsáveis diretos pelas escolhas ou que as influenciem indiretamente. Como visto, a atuação à base da coerção alheia causa perda de bem-estar e dificulta também o atendimento dos "propósitos nobres" que muitos enxergam em diversas medidas dos governos.

Os interesses e a atuação desses indivíduos também prejudicam muitas ações espontâneas de agentes privados que poderiam auxiliar no combate à pandemia ou no processo de redução 
dos danos causados pelas intervenções do governo. Não há, entretanto, como se saber o que não pôde ser feito, o que se deixou de ganhar.

Também como possível efeito da ação dos empreendedores políticos, há o risco de "ladeiras escorregadias" citado. Ainda que a sociedade se veja no futuro relativamente livre do covid-19, são perfeitamente possíveis cenários em que a experiência com o autoritarismo acabou deixando algum legado negativo - alguma "sequela".

Sendo assim, barrar a atuação desses agentes já seria um bom passo inicial a se dar para que os esforços árduos em prol do combate às pandemias não sejam comprometidos. Se não foi o caso nessa última experiência, que, ao menos, isto sirva de lição para as próximas pandemias que ocorrerão no futuro.

\section{Referências}

BARBIERI, Fabio. O processo de mercado na Escola Austríaca Moderna. Dissertação de mestrado. São Paulo: Universidade de São Paulo, 2001.

BIANCO, Jim. The Fed's cure risks being worse than the disease. Bloomberg Opinion, 2020. Disponível em: https://www.bloombergquint.com/gadfly/federal-reserve-s-financial-cure-risks-being-worse-than-disease. Acesso em: 16 ago 2020.

BRASIL. Ministério da Saúde. Instituto Nacional de Câncer, 2020. Pandemia provoca queda de quase $50 \%$ na doação de sangue e plaquetas no INCA. Disponível em: https://www.inca.gov.br/noticias/pandemia-provocaqueda-de-quase-50-na-doacao-de-sangue-e-plaquetas-no-inca. Acesso em: 15 ago 2020.

DE SOTO, J. H. Moeda, crédito bancário e ciclos econômicos. São Paulo: Instituto Ludwig von Mises Brasil, 2013.

FITZGERALD, D. A.; NUNN, K.; ISAACS, D. Consequences of physical distancing emanating from the COVID-19 pandemic: An Australian perspective. Paediatric Respiratory Reviews, 2020. Disponível em: https://www.ncbi. nlm.nih.gov/pmc/articles/PMC7289084/. Acesso em: 15 ago 2020.

GELLER, A. P. Coronavírus: um caso raro de choque de oferta e de demanda - e suas possíveis consequências nefastas. Publicado pelo Instituto Ludwig von Mises Brasil, 2020. Disponível em: https://www.mises.org.br/ article/3229/coronavirus-um-caso-raro-de-choque-de-oferta-e-de-demanda--e-suas-possiveis-consequenciasnefastas. Acesso em: 4 ago 2020.

GIANTURCO, Adriano. A ciência da política: uma introdução. São Paulo: Editora Forense Universitária, 2020.

GONÇALVES, Anderson. Como a pandemia de Covid-19 se tornou o paraíso dos corruptos. Gazeta do povo, 2020. Disponível em: https://www.gazetadopovo.com.br/ideias/pandemia-covid-19-corrupcao/. Acesso em: 02 ago 2020.

HAYEK, F. A. Prices and production and other works: F.A. Hayek on money, the business cycle, and the gold standard. Alabama: Ludwig von Mises Institute, 2008.

HAYEK, F. A. O caminho da servidão. São Paulo: Instituto Ludwig von Mises Brasil, 2010.

HOPPE, Hans-Hermann. Democracia: o deus que falhou. São Paulo: Instituto Ludwig von Mises Brasil, 2014.

IBGE - Instituto Brasileiro de Geografia e Estatística. Pesquisa Pulso Empresa: Impacto da Covid-19 nas empresas, 2020. Disponível em: https://www.ibge.gov.br/estatisticas/investigacoes-experimentais/estatisticas- 
experimentais/28291-pesquisa-pulso-empresa-impacto-da-covid-19-nas-empresas.html?=\&t=downloads\&utm _ source=covid19\&utm_medium=hotsite\&utm_campaign=covid_19. Acesso em: 14 ago 2020.

IESS - Instituto de Estudos de Saúde Suplementar. Nota de acompanhamento de beneficiários 48. São Paulo, 2020. Disponível em: https://www.iess.org.br/cms/rep/NAB48_FINAL.pdf. Acesso em: 17 ago 2020.

IORIO, U. J. Ação, tempo e conhecimento: a Escola Austríaca de economia. São Paulo: Instituto Ludwig von Mises Brasil, 2011.

KHAN, Tulio. Estudos sobre violência e criminalidade no Brasil atual. Rio de Janeiro: Editora Conjuntura, 2012.

KIRZNER, I. M. Competição e atividade empresarial. São Paulo: Instituto Ludwig von Mises Brasil, 2012.

LEONI, Bruno. Liberdade e a lei: os limites entre a representação e o poder. São Paulo: Instituto Ludwig von Mises Brasil, 2010.

MARCOLINI, Thiago. Em meio à pandemia do coronavírus, Brasil notifica mais de 600 mil casos de dengue. Brasil 61, 2020. Disponível em: https://brasil61.com/noticias/em-meio-a-pandemia-do-coronavirus-brasil-notificamais-de-600-mil-casos-de-dengue-pran208694. Acesso em: 14 ago 2020.

MCMAKEN, Ryan. Fatos e dados médicos comprovam: desemprego mata - e quanto mais tempo durar a quarentena, pior será. Publicado pelo Instituto Ludwig von Mises Brasil, 2020. Disponível em: https://www. mises.org.br/article/3246/fatos-e-dados-medicos-comprovam-desemprego-mata\%E2\%80\%94e-quanto-maistempo-durar-a-quarentena-pior-sera. Acesso em: 31 jul 2020.

MILL, J. S. Princípios de Economia Política com algumas de suas aplicações à filosofia social. São Paulo: Editora Nova Cultural Ltda, 1996. Disponível em: https:/edisciplinas.usp.br/pluginfile.php/4321705/mod_resource/ content $/ 1 /$ mill\%20\%281996\%29\%20principios\%20de\%20economia\%20politica\%2C\%20vol\%201.pdf. Acesso em: 02 ago 2020.

MISES, Ludwig von. Ação humana: um tratado de economia. São Paulo: LVM Editora, 2017.

MISES, Ludwig von. O cálculo econômico em uma comunidade socialista. São Paulo: LVM Editora, 2017.

NORTH, Gary. Ao contrário do que diz a imprensa, o Banco Central americano não tem como "elevar os juros". Publicado pelo Instituto Ludwig von Mises Brasil, 2015. Disponível em: https://www.mises.org.br/Article. aspx?id=2213. Acesso em: 14 ago 2020.

OKRENT, Daniel. Last call: the rise and fall of prohibition. New York: Scribner, 2010.

RALLO, J. R. O que é e quais efeitos tem um programa de "afrouxamento quantitativo". Publicado pelo Instituto Ludwig von Mises Brasil. 2015. Disponível em: https://www.mises.org.br/Article.aspx?id=2044. Acesso em: 12 ago 2020.

REED, L. W. Para realmente gerarem valor para a população, empresas têm de ter lucro. Publicado pelo Instituto Ludwig von Mises Brasil, 2015. Disponível em: https://www.mises.org.br/article/2113/para-realmentegerarem-valor-para-a-populacao-empresas-tem-de-ter-lucro. Acesso em: 11 ago 2020.

RIZZO, M. J.; WHITMAN, D. G. The camel's nose is in the tent: rules, theories, and slippery slopes. Journal UCLA Law Review, v. 51, n. 2, p. 539-592, 2003. Disponível em: http://www.csun.edu/ dgw61315/camelsnose. html. Acesso em: 03 ago 2020.

ROQUE, Leandro. Três consequências da desvalorização da moeda - que muitos economistas se recusam a aceitar. Publicado pelo Instituto Ludwig von Mises Brasil, 2015. Disponível em: https://www.mises.org.br/ Article.aspx?id=2175. Acesso em: 18 ago 2020. 
ROQUE, Leandro. Tributação X Regulamentação - O que é pior? Publicado pelo Instituto Ludwig von Mises Brasil, 2009. Disponível em: https://www.mises.org.br/Article.aspx?id=271. Acesso em: 05 ago 2020.

ROTHBARD, M. N. O que o governo fez com o nosso dinheiro? São Paulo: Instituto Ludwig von Mises Brasil, 2013.

SENNHOLZ, H. F. Uma teoria simples sobre a corrupção. Publicado pelo Instituto Ludwig von Mises Brasil, 2017. Disponível em: https://www.mises.org.br/Article.aspx?id=1822. Acesso em: 03 ago 2020.

SHOSTAK, Frank. O problema com os gastos do governo. Publicado pelo Instituto Ludwig von Mises Brasil, 2010. Disponível em: https://www.mises.org.br/Article.aspx?id=298. Acesso em: 12 ago 2020.

SILVA, T. D.; NATALINO, M.; PINHEIRO, M. B. IPEA - Instituto de Pesquisa Econômica Aplicada. Nota Técnica, 2020. População em situação de rua em tempos de pandemia: um levantamento de medidas municipais emergenciais. Disponível em: https://www.ipea.gov.br/portal/images/stories/PDFs/nota_tecnica/200610_nt_74_ diset.pdf. Acesso em: 15 ago 2020.

SMITH, Adam. A riqueza das nações: uma investigação sobre a natureza e as causas da riqueza das nações. São Paulo: Madras, 2009.

SZWARCWALD, C. L. et al. Fundação Oswaldo Cruz. Pandemia de Coronavírus: Mudanças no estilo de vida dos brasileiros. Fiocruz, 2020. Disponível em: https://convid.fiocruz.br/index.php?pag=principal. Acesso em: 17 ago 2020.

THOMAS, Bradley. How many lives will politicians sacrifice in the name of fighting covid-19? Publicado pelo Mises Institute, 2020 Disponível em: https:/mises.org/wire/how-many-lives-will-politicians-sacrificename-fighting-covid-19. Acesso em: 30 jul 2020.

ULRICH, Fernando. Os Bancos Centrais mundiais são hoje a principal fonte de risco e instabilidade à economia mundial. Publicado pelo Instituto Ludwig von Mises Brasil, 2016. Disponível em: https://www.mises. org.br/Article.aspx?id=2440. Acesso em: 05 ago 2020.

WIESER, Friedrich von. Social economics. New York: Adelphi Company, 1927. Disponível em: https://cdn. mises.org/Social\%20Economics_4.pdf. Acesso em: 03 ago 2020.

YANDLE, Bruce. Bootleggers and baptists - the education of a regulatory economist. Viewpoint, 1983. Disponível em: http://pirate.shu.edu/ rotthoku/Liberty/On\%20Bootleggers\%20\&\%20Baptists.pdf. Acesso em: 02 ago 2020.

RECEBIDO: 20 DE AGOSTO 2020

APROVADO: 14 DE SETEMBRO 2020 